\title{
Commentary: How much hydration is really optimal for the kidneys? How will we know?
}

\author{
K. Annette Mizuguchi, MD, PhD, MMSc, FASE, and Gyorgy Frendl, MD, PhD
}

\footnotetext{
From the Department of Anesthesiology, Perioperative and Pain Medicine, Brigham and Women's Hospital, Harvard Medical School, Boston, Mass.

Disclosures: Authors have nothing to disclose with regard to commercial support.

Received for publication April 9, 2019; accepted for publication April 9, 2019; available ahead of print June 4, 2019.

Address for reprints: K. Annette Mizuguchi, MD, PhD, MMSc, FASE, Brigham and Women's Hospital, Department of Anesthesiology, 75 Francis St, Boston, MA 02115 (E-mail: amizuguchi@partners.org).

J Thorac Cardiovasc Surg 2020;159:1880-1

$0022-5223 / \$ 36.00$

Copyright (c) 2019 Published by Elsevier Inc. on behalf of The American Association for Thoracic Surgery

https://doi.org/10.1016/j.jtcvs.2019.04.045
}

Improving kidney outcomes remains challenging because of the lack both of readily available, reliable methods for diagnosing early acute kidney injury (AKI) and of the ability to measure volume status in our patients. Because the mechanism of AKI has yet to be fully understood, there are opportunities for novel approaches to reduce perioperative AKI. One study found that AKI duration of 3 days or longer, rather than novel renal biomarkers, was strongly associated with readmission and mortality in cardiac surgical patients. ${ }^{1}$

In this issue of the Journal, Johnston and colleagues ${ }^{2}$ report the results of cardiac surgical patients divided into 2 groups, before and after implementation of a goaltheir protocol, centered on patient fluid responsiveness, decreased the risk for AKI (as defined by RIFLE criteria) after cardiac surgery.

This study is encouraging and timely in light of a great push for enhanced recovery after surgery pathways in cardiac surgery. ${ }^{3}$ General surgery enhanced recovery after surgery pathways aim to restrict fluids to achieve zero balance. restricted patients had a higher rate of AKI. ${ }^{4}$ This study of Johnston and colleagues ${ }^{2}$ in the Journal provides a potential road map for optimizing fluid resuscitation by using surrogates of volume status as respiratory variation (pulse pressure variation), passive leg raising, and bedside transthoracic echocardiography to evaluate the adequacy of intravascular volume.

We need to remain mindful, however, that in this nonrandomized, preintervention-postintervention cohort study, other unmeasured variables could have accounted for lower AKI rates in the postimplementation group. In addition, although Johnston and colleagues ${ }^{2}$ did not exclude patients with preoperative chronic kidney disease, it is possible (1) that their patients were relatively healthy or (2) that the surgical procedures were relatively uncomplicated, as directed volume resuscitation protocol. They found that For those patients, a recent study showed that fluid-

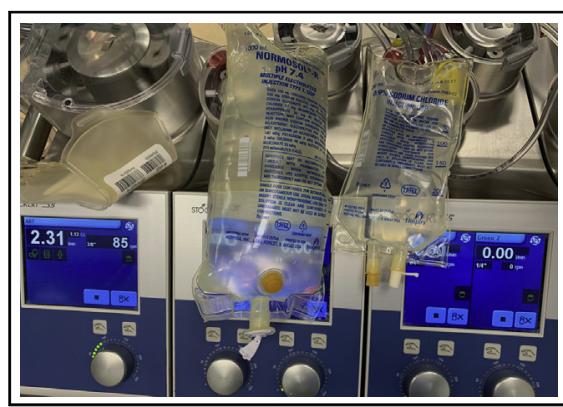

Understanding when to give what fluid and how much to give may decrease AKI.

Central Message

Accurate assessment of patient volume status and use of a goal-directed resuscitation protocol may be helpful in preventing acute kidney injury in cardiac surgery.

See Article page 1868. suggested by the fact that none of their patients received intraoperative blood products.

To understand AKI better, we clearly have more work to do. Improved care will come from more reliable measurement of the patients' physiologic responses, from better understanding of their hemodynamics and need for renal perfusion and oxygenation, and from following improved biomarkers of kidney injury, and it may require thinking outside the box by giving intravenous amino acids to improve renal hemodynamics. ${ }^{5}$ More importantly, we need to collaborate to complete large controlled trials to test strategies beyond biomarker validation to tackle the difficult problem of kidney disease after surgery.

Much effort and some progress have been made, as we already understand the harmful effects of the use of normal saline for fluid resuscitation on the renal outcomes in critically ill patients, and some combinations of renal biomarkers seem promising. ${ }^{6,7}$ Just as the mortality of sepsis has been significantly reduced as a result of worldwide implementation of protocols to diagnose and manage patients with sepsis, an evidence-based, protocol-driven strategy may help to reduce both the overall incidence of AKI after cardiac surgery and the significant variability in the incidence of AKI that exists today, even among centers of cardiac surgical excellence. 


\section{References}

1. Brown JR, Philbrook HT, Goodrich CA, Bohm AR, Alam SS, Coca SG, et al. Are urinary biomarkers better than acute kidney injury duration for predicting readmission? Ann Thorac Surg. 2019;107:1699-705.

2. Johnston LE, Thiele RH, Hawkins RB, Downs EA, Jaeger JM, Brooks C, et al. Goal-directed resuscitation following cardiac surgery reduces acute kidney injury: a quality initiative pre-post analysis. J Thorac Cardiovasc Surg. 2020;159: 1868-77.

3. Williams JB, McConnell G, Allender JE, Woltz P, Kane K, Smith PK, et al. Oneyear results from the first US-based enhanced recovery after cardiac surgery (ERAS Cardiac) program. J Thorac Cardiovasc Surg. December 8, 2018 [Epub ahead of print].

4. Myles PS, Bellomo R, Corcoran T, Forbes A, Peyton P, Story D, et al; Australian and New Zealand College of Anaesthetists Clinical Trials Network and the Austra- lian and New Zealand Intensive Care Society Clinical Trials Group. Restrictive versus liberal fluid therapy for major abdominal surgery. $N$ Engl J Med. 2018; 378:2263-74.

5. Pu H, Doig GS, Heighes PT, Allingstrup MJ, Wang A, Brereton J, et al Intravenous amino acid therapy for kidney protection in cardiac surgery patients: a pilot randomized controlled trial. J Thorac Cardiovasc Surg. 2019;157: 2356-66.

6. Semler MW, Self WH, Wanderer JP, Stollings JL, Self WH, Siew ED, et al; SALT Investigators. Balanced crystalloids versus saline in critically ill adults. The SALT Randomized Trial. N Engl J Med. 2018;378:829-39.

7. Cummings JJ, Shaw AD, Shi J, Lopez MG, O’Neal JB, Billings FT IV. Intraoperative prediction of cardiac surgery-associated acute kidney injury using urinary biomarkers of cell cycle arrest. J Thorac Cardiovasc Surg. 2019;157: 1545-53.e5. 